\title{
Gas Exchange during High Frequency Flow- Interruption in Rabbits before and after Bronchoalveolar Lavage
}

\author{
KEVIN J. SULLIVAN, MANUEL DURAND, TIE-HU YE, AND H. K. CHANG \\ Departments of Biomedical Engineering and Pediatrics, University of Southern California, Los Angeles, \\ California 90089-145I
}

\begin{abstract}
The performance of a high frequency flowinterrupter (HFFI) type neonatal ventilator was evaluated on nine adult rabbits (control) and on five adult rabbits after bronchoalveolar lavage (BAL). Tidal volumes and airway pressures were measured during conventional ventilation and during HFFI at rates of $4,6,8,10$, and 12 cycles/s. Tidal volumes were adjusted to maintain $\mathrm{PaCO}_{2}$ between 35 and $42 \mathrm{~mm} \mathrm{Hg}$ in control rabbits and 35-55 $\mathrm{mm} \mathrm{Hg}$ in BAL rabbits; a positive end-expiratory pressure of $4 \mathrm{~cm} \mathrm{H}_{2} \mathrm{O}$ was applied to $\mathrm{BAL}$ rabbits to reduce atelectasis and improve gas exchange. The normalized tidal volume required to maintain $\mathrm{PaCO}_{2}$ within the specified range during HFFI varied between $2.02 \mathrm{ml} / \mathrm{kg}(0.30 \mathrm{SD})$ and $2.55(0.41)$ in control rabbits and between $2.65(0.57)$ and $2.97(0.51)$ in BAL rabbits. In neither group did the normalized tidal volume vary systematically with the rate of ventilation $(p<0.05)$. Mean airway pressures were lower during HFFI than during conventional ventilation in control rabbits but comparable in the BAL group. Peak inflation pressures were greater during HFFI than conventional ventilation in control rabbits but similar in the BAL group. End-expiratory lung volume was not affected by ventilation rate during $H F F I$ in control rabbits. We conclude 1) that HFFI can maintain gas exchange in rabbits suffering from acute respiratory distress with airway pressures that are comparable to those measured during conventional ventilation and 2) the capacity of HFFI to ventilate the lungs with significantly lower airway pressures than conventional ventilation depends, in part, on the condition of the lungs. (Pediatr Res 24: 203-208, 1988)
\end{abstract}

\section{Abbreviations}

BAL, bronchoalveolar lavage cps, cycles per second $\mathrm{FrO}_{2}$, fractional concentration of oxygen in inspired gas HFFI, high frequency flow-interruption HFJV, high frequency jet ventilation HFV, high frequency ventilation Pao, airway opening pressure Paw, airway (tracheal) pressure Paw, mean airway pressure $P_{D}$, dynamic pressure head PEEP, positive end-expiratory pressure PIP, peak inspiratory pressure $T_{I} / T_{\text {TOT }}$, fractional duration of inspiration $V_{\text {max }}$, peak flow

Received January 22, 1988; accepted April 5, 1988

Correspondence H. K. Chang, Department of Biomedical Engineering, University Park, University of Southern California, Los Angeles, CA 90089-1451.

Supported by NHLBI Grant HL33274.
$V_{\mathrm{T}}$, tidal volume

HFOV, high frequency oscillation

ANOVA, analysis of variation

a/A $\mathrm{PO}_{2}$, arterial/alveolar $\mathrm{PO}_{2}$ ratio

Mechanically assisted ventilation is the principal method of treatment for severe respiratory distress syndrome in newborn infants (2). In the large majority of infants who require ventilation therapy, a conventional time-cycled pressure limited ventilator is used. Ventilators of this sort typically operate at rates on the order of one cps and generate high airway pressures in order to achieve adequate $V_{T}$ and sufficient gas exchange. Because large, phasic changes in airway pressure and lung volume are associated with an increased incidence of pulmonary barotrauma $(2,3)$, alternative modes of neonatal ventilation therapy including HFV are currently under investigation.

The three basic types of HFV are HFOV, HFJV, and HFFI (4). Each type differs from the others in the timing of the ventilator cycle, the flow-volume relationship and in whether expiration is passive or active. Whereas there is no doubt that $\mathrm{HFV}$ in general can maintain gas exchange with smaller $V_{T}$ than conventional ventilators (5), it is not clear if $\mathrm{HFV}$ produces significantly lower airway pressures or reduces the incidence of lung barotrauma $(6,7)$. The uncertainty in this aspect of $\mathrm{HFV}$ may be due to the fact that the airway pressures and flows generated during the ventilation cycle vary considerably between different HFV devices (8). Thus, an important step in evaluating HFV involves characterizing the pressures and flows required to maintain gas exchange.

In our study we assessed the performance of a particular HFV known as the Infant Star (Infrasonics, San Diego, CA). This device is essentially a flow-interrupter type of HFV that uses a series of solenoid valves to introduce brief pulses of high velocity airflow into the central airways. At the onset of expiration, the Infant Star produces a transient but substantial drop in airway pressure (Fig. 1). To our knowledge there are no reports on the magnitudes of pressure and airflow that are necessary to maintain gas exchange with the Infant Star. Accordingly, we evaluated these characteristics during HFV of normal adult rabbits. To assess the relationship of lung function and ventilator performance, measurements were also performed on rabbits suffering from acute respiratory distress after bronchoalveolar lavage.

\section{MATERIALS AND METHODS}

Nine New Zealand White rabbits weighing between 2.1 and $2.6 \mathrm{~kg}$ (mean body weight $=2.28 \pm 0.20 \mathrm{~kg}$ ) were studied. Each rabbit was anesthetized with an injection of methohexitol sodium $(50 \mathrm{mg} / \mathrm{kg}$, intraperitoneally) and maintained under anesthesia with a continuous intravenous infusion $(0.5 \mathrm{mg} / \mathrm{kg} / \mathrm{min})$. A 

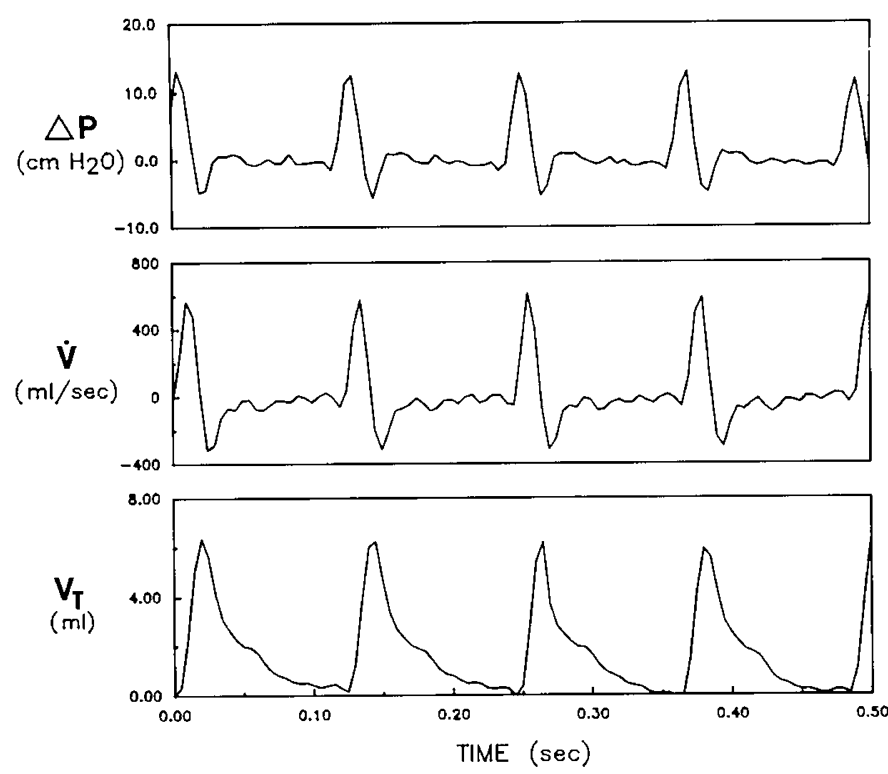

Fig. 1. Pressure, volume, and airflow waveforms produced by the Infant Star ventilator. Typical records of airway pressure $P$, flow $V$, and tidal volume $V_{T}$ during HFFI at $8 \mathrm{cps}$. Note the negative swing in airway at the beginning of the expiratory phase and its effect on expiratory flow.

tracheotomy was performed below the level of the larynx and a short cannula (i.d. $=4.5 \mathrm{~mm}$, internal volume $1.4 \mathrm{ml}$ ) was inserted and fixed in position using surgical thread and cyanoacrylate adhesive. The rabbit was placed supine inside a 22-liter whole-body plethysmograph and ventilated with air $\left(\mathrm{FIO}_{2}=0.21\right)$ at a conventional rate. Throughout the experiment spontaneous breathing was supressed by intermittent injections of pancuronium bromide (Pavulon $0.1 \mathrm{mg} / \mathrm{kg}$, intravenously).

Paw was measured with a piezoresistive pressure transducer that has a flat frequency response up to $200 \mathrm{~Hz}$ (140PCO1D; Microswitch, Freeport, IL) and is connected to a side port on the cannula. Variations in plethysmograph pressure were measured with a negative differential pressure transducer (MP245; Validyne, Northridge, CA). The frequency response of the transducers and plethysmograph were determined by a variation of the method of Jackson and Vinegar (9) and were flat up to approximately $60 \mathrm{~Hz}$. Mean arterial pressure was measured using a saline filled pressure transducer (DP15-32; Validyne, Northridge, $\mathrm{CA}$ ) and catheter inserted into the femoral artery. Body temperature was monitored with a rectal probe (43TA; Yellow Springs Instrument Co., Yellow Springs, $\mathrm{OH}$ ) and maintained at $38 \pm 1^{\circ} \mathrm{C}$ with a radiant heat lamp.

Gas exchange. The $\mathrm{V}_{\Upsilon}$ required to maintain normocapnia in control rabbits during HFFI was determined at ventilation rates of $4,6,8,10$, and 12 cps. These rates correspond roughly to between 4 and 12 times the rate of spontaneous breathing in the adult rabbit (10) and thus qualify as HFV according to guidelines recommended by Drazen et al. (5). At each rate, the ventilator was initially adjusted to produce changes in lung volume of between 1.0 and $3.0 \mathrm{ml} / \mathrm{kg}$ and the rabbit was ventilated continuously with air for $10 \mathrm{~min}$. At the end of a 10 -min period, a sample of arterial blood was withdrawn and blood gases and $\mathrm{pH}$ were determined using an automated blood gas analyzer (ABL2; Radiometer, Copenhagen). To verify that there was sufficient time for equilibration of blood gases (11), additional samples were drawn at 20 - and 25 -min intervals in one rabbit. We observed no further changes in blood gas tensions between 10 and $25 \mathrm{~min}$ of continuous ventilation. If $\mathrm{PaCO}_{2}$ was between $35-42 \mathrm{~mm} \mathrm{Hg}$ the ventilator was switched to a new rate. However, if $\mathrm{PaCO}_{2}$ exceeded this range, the $\mathrm{V}_{\mathrm{T}}$ was readjusted and the lung was ventilated for $10 \mathrm{~min}$ at the new setting before another blood sample was withdrawn. For all rabbits, the order in which ventilation rates were studied was randomized to prevent any systematic effects due to ventilation history. In addition, at each rate, lung volume history was standardized by three large inflations to an airway pressure of $30-35 \mathrm{~cm} \mathrm{H}_{2} \mathrm{O}$ in order to reverse the atelectasis that may occur during positive pressure ventilation (12). No PEEP was applied to the normal rabbits during HFFI.

Blood gas tensions and $\mathrm{pH}$ were also measured during conventional mechanical ventilation at a frequency of 40 cycles $/ \mathrm{min}$ $\left(\mathrm{T}_{\mathrm{I}} / \mathrm{T}_{\mathrm{TOT}}=0.3\right)$ and with a PIP of $8-10 \mathrm{~cm} \mathrm{H}_{2} \mathrm{O}$. All ventilator pressure settings refer to Pao which is measured in the endotracheal tube connector and displayed on the ventilator console. No PEEP was applied to normal rabbits during conventional ventilation.

At each ventilation rate, alveolar oxygen tension was estimated using the alveolar gas equation:

$$
\mathrm{PAO}_{2}=\mathrm{PIO}_{2}-\mathrm{PaCO}_{2}+\left[\mathrm{PaCO}_{2} * \mathrm{FIO}_{2}(1 / \mathrm{R}-1)\right]
$$

assuming $\mathrm{R}=0.8$, and the arterial to alveolar oxygen tension ratio, a/ $\mathrm{APO}_{2}$ (13) was calculated.

$B A L$. Gas exchange during HFFI was examined in five rabbits (body weight $=2.15 \pm 0.14 \mathrm{~kg}$ ) depleted of lung surfactant using the lavage technique described by Lachmann et al. (14). To wash out lung surfactant, the rabbit was ventilated for $10-15 \mathrm{~min}$ with $100 \% \mathrm{O}_{2}$, then hyperinflated to an airway pressure of $25-30 \mathrm{~cm}$ $\mathrm{H}_{2} \mathrm{O}$ in order to promote release of surfactant (15). Isotonic saline $(0.9 \mathrm{~g} / 100 \mathrm{ml}, 30 \mathrm{ml} / \mathrm{kg})$ at $37^{\circ} \mathrm{C}$ was instilled into the lung using airway pressures of less than $30 \mathrm{~cm} \mathrm{H}_{2} \mathrm{O}$, while the thorax was gently massaged by hand to encourage distribution. By tilting the rabbit and manually compressing the thorax, salinecontaining surfactant drained into the large airways and trachea from which it was removed by means of a suction catheter. The rabbit was then ventilated with $100 \% \mathrm{O}_{2}$ at a rate of 40 cycles/ $\min \left(\mathrm{T}_{\mathrm{r}} / \mathrm{T}_{\mathrm{TOT}}=0.3\right)$ and with a PEEP of $4 \mathrm{~cm} \mathrm{H} \mathrm{H}_{2} \mathrm{O}$ and PIP of $15-20 \mathrm{~cm} \mathrm{H}_{2} \mathrm{O}$ to facilitate transport of the saline remaining in the lung into the periphery. The lavage sequence was repeated until arterial $\mathrm{PO}_{2}$ was $250 \mathrm{~mm} \mathrm{Hg}$ or less after $20 \mathrm{~min}$ of conventional ventilation. As few as two and as many as eight separate lung lavages were required to obtain values of $\mathrm{PaO}_{2}$ characteristic of acute respiratory distress (16).

After lung lavage, the effect of HFFI on gas exchange was assessed following the same protocol used for normal rabbits with the exception that PEEP was maintained at $4 \mathrm{~cm} \mathrm{H}_{2} \mathrm{O}$ and the $\mathrm{FIO}_{2}$ equaled 1.0. For conventional ventilation of these rabbits, the rate was set at $40 \mathrm{cpm}$ and PIP equaled $15-20 \mathrm{~cm} \mathrm{H}_{2} \mathrm{O}$. Our choice of these settings was based on the previous study of BAL rabbits by Lachmann et al. (14). Because of their impaired lung function the BAL rabbits displayed elevated $\mathrm{PaCO}_{2}$ that, in some cases, could be lowered by a moderate increase in $\mathrm{V}_{\mathrm{T}}$. Inasmuch as the risk of lung rupture and pneumothorax likely increases with this adjustment, we adopted the guidelines recommended by Stark and Frantz (1) and increased the upper limit of $\mathrm{PaCO}_{2}$ to $55 \mathrm{~mm} \mathrm{Hg}$ in this group. Accordingly, our evaluation of ventilator performance in BAL rabbits reflects its capacity to maintain blood gases at levels that are generally accepted for lungs in this condition.

Ventilation parameters. For each combination of ventilation frequency and $V_{T}$ that produced acceptable gas exchange, mean and peak airway pressures were computed along with peak inspiratory and expiratory flows. To assess if HFV caused an elevation of end-expiratory lung volume, the ventilator was momentarily turned off during HFFI. This caused airway pressure to rapidly fall to atmospheric pressure and lung volume to return to its resting volume. If lung volume was elevated during HFFI, the resting lung volume would fall below the end-expiratory volume and the change in volume could be determined from the change in plethysmograph pressure. This procedure was repeated three times at each frequency in six of the normal rabbits. No measurements of this sort were performed on BAL rabbits.

Data acquisition and analysis. The output signals from airway 
and plethysmograph pressure transducers were low pass filtered with a cutoff frequency of $100 \mathrm{~Hz}$ (902LPF; Frequency Devices, Haverhill, MA) and passed into a computer (PDP 11/73; Digital, Maynard, MA) for A/D conversion. For each trial, 1200 data points were collected from each signal at a rate of $400 \mathrm{~Hz}$. Variations in plethysmograph pressure were converted into changes in lung volume using a suitable calibration factor obtained by calibrating and plethysmograph several times throughout each experiment. The dimensions of the plethysmograph and the rate of the pressure changes within it insured that all measurements and calibrations were performed under essentially adiabatic conditions (17). Airflow was computed by numerical differentiation of the digitized volume signal.

All variables are presented as means $\pm 1 \mathrm{SD}$. Within group differences were tested using one-way ANOVA. Between groups differences were compared using two-way ANOVA (18). Differences were considered significant if $p<0.05$.

\section{RESULTS}

Gas exchange. The effects of HFFI on blood gas tensions and $\mathrm{pH}$ in normal and BAL rabbits are shown in Table 1. For the nine normal rabbits, arterial $\mathrm{PO}_{2}, \mathrm{PCO}_{2}$, and $\mathrm{pH}$ were within acceptable limits at all ventilation frequencies. $\mathrm{PaO}_{2}$ was not significantly different between HFFI and conventional ventilation nor did it vary with the rate of ventilation. The a/A $\mathrm{PO}_{2}$ (Fig. 2) increased slightly with HFV but the change was not significant.

For the BAL group, arterial $\mathrm{PCO}_{2}$ varied between 39.2 and 52.7 during HFFI with the highest level occuring at the lowest frequency. The relatively high value of $\mathrm{PaCO}_{2}$ at $4 \mathrm{cps}$ was due to poor ventilation that occurred in one rabbit. Inasmuch as this animal was also the largest in the group (2.4 versus $2.09-2.11 \mathrm{~kg}$ for the remaining four) it is possible that its ventilatory requirements exceeded the capacity of the ventilator at this rate of HFFI. Despite the high value in this animal, the mean $\mathrm{PaCO}_{2}$ did not vary significantly with ventilation rate. Mean arterial $\mathrm{PO}_{2}$ during HFFI was maintained at levels comparable to $\mathrm{PaO}_{2}$ during conventional ventilation although there was greater intra-group variation in $\mathrm{PaO}_{2}$ during HFFI. As in the normal group, there were no differences in $\mathrm{PaO}_{2}$ or a/A $\mathrm{PO}_{2}$ between conventional and HFFI and neither $\mathrm{PaO}_{2}$ nor a/A $\mathrm{PO}_{2}$ varied with the rate of HFFI.
The relationship between normalized $\mathrm{V}_{\mathrm{T}}$ and the rate of ventilation is shown in Figure 3. For both normal and BAL rabbits, the $\mathrm{V}_{\mathrm{T}}$ required to maintain $\mathrm{PaCO}_{2}$ during HFFI were approximately $40-50 \%$ of the $\mathrm{V}_{\mathrm{T}}$ used during conventional ventilation and were independent of rate up to $12 \mathrm{cps}$. For normal rabbits during $\mathrm{HFFI}, \mathrm{V}_{\mathrm{T}} / \mathrm{kg}$ body weight varied between 2.02 and 2.55 $\mathrm{ml}$ whereas in the BAL group, $\mathrm{V}_{\mathrm{T}}$ were slightly larger. Differences between groups during HFFI were not significant except at 10 and 12 cps.

Ventilation parameters. $\overline{\mathrm{aw}}$ during HFFI for normal and BAL rabbits are shown in the top of Figure 4. For normal rabbits, Paw was significantly lower during HFFI than during conventional ventilation. For BAL rabbits, however, there was no significant difference in Paw between HFV and conventional modes of ventilation. During HFFI in normal rabbits PIP were about twice the value found with conventional ventilation (Fig. 4, bottom) but for BAL rabbits, PIP did not differ significantly between high frequency and conventional ventilation. In both groups neither $P \overline{\mathrm{aw}}$ nor PIP varied with the rate of HFFI.

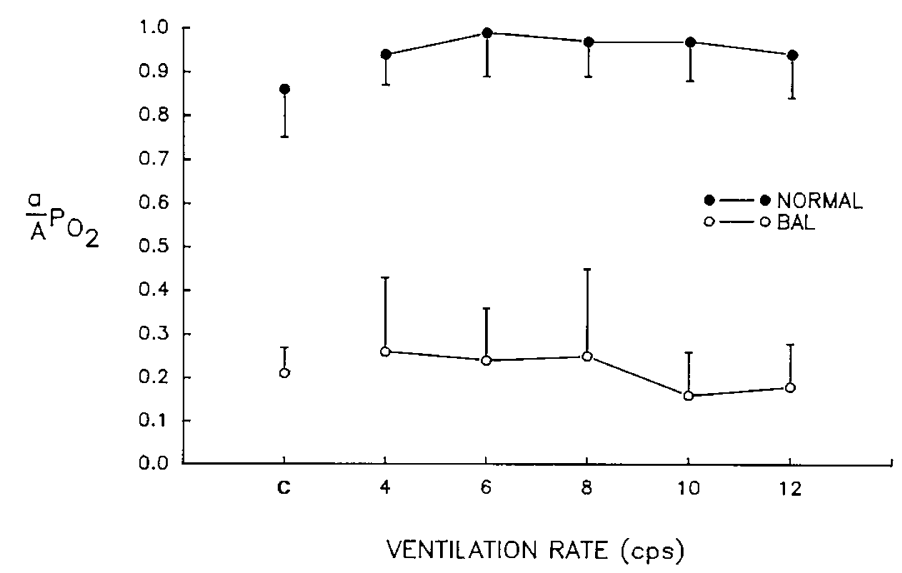

Fig. 2. Arterial-alveolar oxygen tension ratios in normal and BAL rabbits. Mean a/A $\mathrm{PO}_{2}$ ratios during conventional ventilation $(C)$ and HFFI. Closed circles, normal rabbits; open circles, BAL rabbits. Data points are group means, bars denote $1 \mathrm{SD}$. The a/APO 2 ratios in $\mathrm{BAL}$ rabbits during HFFI are similar to those obtained from infants suffering respiratory distress (29).

Table 1. Blood gas and $p H$ in normal and BAL rabbits*

\begin{tabular}{|c|c|c|c|c|c|c|}
\hline $\begin{array}{l}\text { Rate } \\
\text { (cps) }\end{array}$ & $\mathrm{C}$ & 4 & 6 & 8 & 10 & 12 \\
\hline \multicolumn{7}{|c|}{$\operatorname{Normal}(n=9)$} \\
\hline $\mathrm{PaO}_{2}$ & 95 & 101 & 106 & 107 & 106 & 101 \\
\hline $\mathrm{mm} \mathrm{Hg}$ & (11) & (9) & $(7)$ & $(10)$ & (11) & (11) \\
\hline $\mathrm{PaCO}_{2}$ & 39.1 & 41.5 & 39.9 & 38.1 & 39.4 & 41.4 \\
\hline $\mathrm{mm} \mathrm{Hg}$ & $(3.1)$ & $(2.2)$ & $(1.6)$ & $(2.8)$ & $(1.3)$ & $(1.7)$ \\
\hline \multirow[t]{2}{*}{$\mathrm{pH}$} & 7.32 & 7.35 & 7.35 & 7.36 & 7.34 & 7.33 \\
\hline & $(0.03)$ & $(0.03)$ & $(0.04)$ & $(0.04)$ & $(0.03)$ & $(0.04)$ \\
\hline $\mathrm{BP}$ & 84 & 84 & 90 & 88 & 87 & 84 \\
\hline $\mathrm{mm} \mathrm{Hg}$ & (9) & $(8)$ & $(8)$ & (7) & (7) & (7) \\
\hline \multicolumn{7}{|l|}{$\operatorname{BAL}(n=5)$} \\
\hline $\mathrm{PaO}_{2}$ & 135 & 177 & 165 & 172 & 106 & 125 \\
\hline $\mathrm{mm} \mathrm{Hg}$ & $(41)$ & $(112)$ & $(84)$ & $(135)$ & $(68)$ & $(70)$ \\
\hline $\mathrm{PaCO}_{2}$ & 44.0 & 52.7 & 39.5 & 38.1 & 41.0 & 39.2 \\
\hline $\mathrm{mm} \mathrm{Hg}$ & $(4.4)$ & $(16.0)$ & $(2.7)$ & $(1.3)$ & $(12.1)$ & $(3.0)$ \\
\hline \multirow[t]{2}{*}{$\mathrm{pH}$} & 7.27 & 7.27 & 7.36 & 7.38 & 7.37 & 7.34 \\
\hline & $(0.04)$ & $(0.09)$ & $(0.02)$ & $(0.02)$ & $(0.03)$ & $(0.02)$ \\
\hline $\mathrm{BP}$ & 78 & 76 & 80 & 79 & 79 & 79 \\
\hline $\mathrm{mm} \mathrm{Hg}$ & (16) & (12) & (11) & (11) & (10) & (10) \\
\hline
\end{tabular}

* Values of arterial $\mathrm{PO}_{2}, \mathrm{PCO}_{2}$, and $\mathrm{pH}$ obtained from normal and $\mathrm{BAL}$ rabbits during conventional ventilation (C) and $\mathrm{HFFI}$. BP, mean arterial pressure. Group mean values are presented with $1 \mathrm{SD}$ in parentheses. In both normal and BAL groups, arterial blood gases, $\mathrm{pH}$, and $\mathrm{BP}$ were unaffected by ventilation rate. 
Peak inspiratory and expiratory flows $\left(\dot{\mathrm{V}}_{\max }\right)$ during HFFI are shown in Figure 5. Peak flows during HFFI were similar in both groups. The peak inspiratory flows were about five times greater during HFFI than during conventional ventilation whereas the peak expiratory flows were about three times greater.

In six normal rabbits, changes in the end-expiratory lung volume when HFV was suddenly interrupted varied between 0.20 and $0.73 \mathrm{ml}$ and were not significantly different from zero.

\section{DISCUSSION}

In this study we have used standard measurements of gas exchange and ventilation to assess the operating characteristics of the Infant Star neonatal ventilator. Our results indicate that this ventilator can maintain adequate gas exchange in normal and BAL rabbits during HFV. Paw during HFFI were comparable or less than those measured during conventional ventilation for the same PEEP; PIP during HFFI were equal to or greater than those measured during conventional ventilation. An interesting result of our analysis was that the performance of HFFI depended on the condition of the lungs. Specifically, when compared with conventional ventilation, the mean airway pressures necessary for adequate gas exchange during HFFI were greater in lungs depleted of surfactant than in normal lungs.

The Infant Star ventilator incorporates microprocessors to monitor and control the Pao in the endotracheal tube connector. During HFFI the mean value of $\mathrm{Pao}$ is equal to the applied PEEP. For normal rabbits during HFFI, Paw measured in the trachea was the same as mean Pao. However, for the BAL rabbits $\mathrm{P} \overline{\mathrm{aw}}$ was greater than mean Pao which equaled the applied PEEP of $4 \mathrm{~cm} \mathrm{H} \mathrm{H}_{2} \mathrm{O}$ (Fig. 4, top). This phenomenon has been observed during HFJV in normal rabbits (6) as well as in rabbits suffering from respiratory distress induced by oleic acid lung injury (10). Frantz and Close (6), reported that $\mathrm{Paw}$ in the trachea during HFJV may exceed Pao by as much as two to three times and noted that the elevated Paw corresponded well with the mean alveolar pressure and an increase in end-expiratory lung volume. Our finding that Paw during HFFI was greater than Pao in sick rabbits but comparable to Pao in normal rabbits suggests that intrinsic-PEEP can develop in sick lungs during HFFI that is not apparent from measurements of $\mathrm{Pao}$. In view of previous observations $(6,10)$, this finding underscores the importance of airway (i.e. tracheal) pressure measurement in evaluating the performance of HFV.

Another interesting characteristic of HFFI is that the $V_{T}$ re-

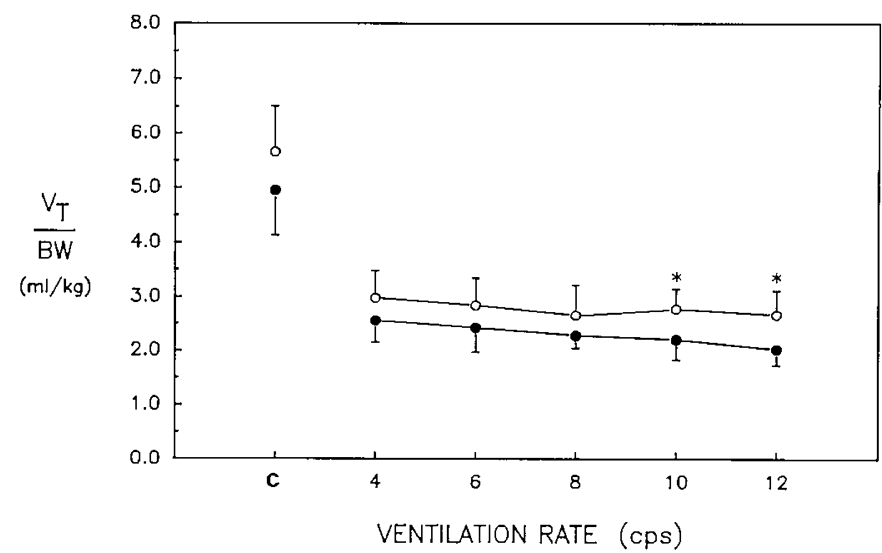

Fig. 3. Comparison of normalized $\mathrm{V}_{\mathrm{T}}$ from normal and BAL rabbits during conventional ventilation and HFFI. The $V_{T}$ normalized per $\mathrm{kg}$ body weight $\left(V_{T} / B W\right)$ during conventional ventilation $(C)$ and HFFI. Closed circles, normal rabbits; open circles, BAL rabbits. In both groups inflation volumes were independent of ventilation rate during HFFI. Data points are group means; bars denote $1 \mathrm{SD} ; *$ significant difference between normal and BAL rabbits.
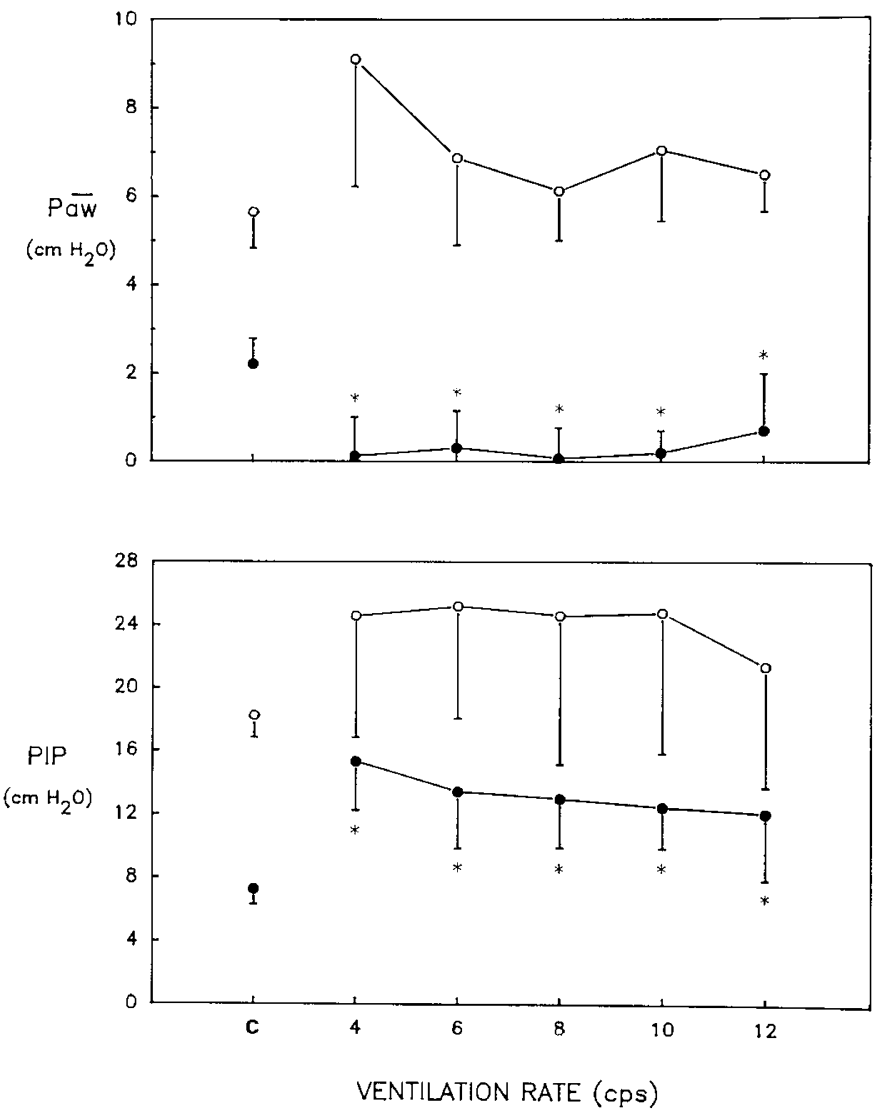

Fig. 4. Comparison of mean and peak airway pressures in normal and BAL rabbits. Top, Paw during conventional ventilation $(C)$ and HFFI. Bottom, PIP. Closed circles, normal rabbits; open circles, BAL rabbits. Data points are group means; bars denote $1 \mathrm{SD}$; * significant difference between $\mathrm{C}$ and HFFI.

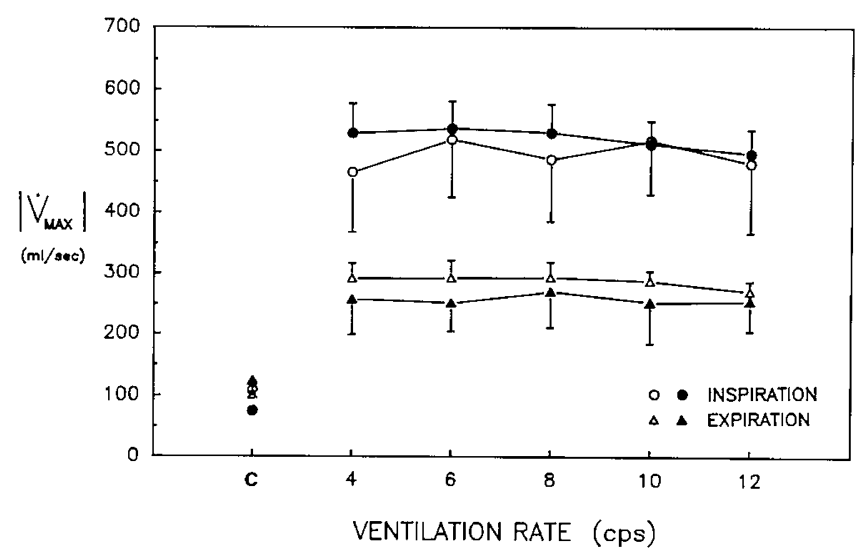

Fig. 5. Comparison of peak inspiratory and expiratory airflows in normal and BAL rabbits. Maximum inspiratory and expiratory flows $\left(\dot{\mathrm{V}}_{\max }\right)$ during conventional ventilation $(C)$ and HFFI. Closed circles and triangles, normal rabbits; open circles and triangles, BAL rabbits.

quired to maintain $\mathrm{PaCO}_{2}$ in normal rabbits during HFFI exceeded the estimated dead space of the respiratory system (about $1.7 \mathrm{ml} / \mathrm{kg}$; from Ref. 19). This characteristic is not confined to HFFI ventilation because $V_{T}$ larger than dead space have also been reported during jet ventilation $(6,20,21)$. However, unlike other forms of $\mathrm{HFV}$, in which $\mathrm{V}_{\mathrm{T}}$ decreases with increasing ventilation rate $(9,22,23)$, the $V_{T}$ recorded HFFI were independent of ventilation rate (Fig. 3). The practical significance of this feature of HFFI is that high rates of ventilation may not be . necessary to obtain acceptable gas exchange in neonates. Al- 
though we are not yet able to understand why this occurs, a possible mechanism may involve manner in which HFFI is produced.

For the Infant Star, the duration of inspiration during HFFI is fixed and the rate can only be varied by adjusting the duration of expiration. Because of the fixed inspiratory timing the $V_{T}$ delivered with each cycle is determined entirely by the rate of the inspiratory flow. Owing to the short (12 $\mathrm{ms}$ in this model) duration of inspiration, these flows are quite large and, like the corresponding $\mathrm{V}_{\mathrm{T}}$, appear to be independent of ventilation rate (Fig. 5). It should be noted, however, that the later models of this ventilator incorporated a longer inspiratory duration (18 $\mathrm{ms}$ ). To achieve airflows of this order the gas within the large central airways must be subjected to considerable acceleration and the resulting flows are governed predominantly by gas inertia. Under these conditions, fresh gas may move into the lung periphery through a process of bulk convection. An empirical and theoretical analysis of gas transport by this mechanism has revealed the rate of $\mathrm{CO}_{2}$ washout from a physical model depends primarily on $\mathrm{V}_{\mathrm{T}}$ and is relatively unaffected by ventilation rate (24).

The large airflows during HFFI may generate additional effects within the airways. As shown in Figure 5, the peak inspiratory flows varied between 450 and $500 \mathrm{ml} / \mathrm{s}$ or roughly three to five times greater than the peak airflow during conventional ventilation. These high inspiratory flows produce a shear force at the wall of the large airways that can promote the movement of mucus in the direction of flow. For bidirectional flows, the net direction of mucus transport depends on the net shear force acting on the airway wall and is determined by the relative rates of inspiratory and expiratory airflows (25). An index of the magnitude of shear forces in the trachea is the $P_{D}$ at the opening of the endotracheal tube. Estimated values of $P_{D}$ for inspiratory and expiratory flows are given in Table 2. During inspiration, $P_{D}$, is about 20 times greater than the values obtained during conventional mechanical ventilation. Expiratory values are roughly $25-35 \%$ of the inspiratory values indicating that the net shear force is in the inspiratory direction. Conceivably, the active expiratory phase of the ventilator may reduce the net shear forces in the large airways and the effect of these forces on mucus clearance. However, because the high flow velocities produced during HFV are also implicated in the development of tracheal lesions $(21,26)$ and pose problems in the delivery of humidified air, it remains to be determined whether bidirectional flows of the magnitude produced by the Infant Star are beneficial to the infant.

Gas trapping can occur during HFJV if the duration of the expiratory phase is too short to allow for complete expiration to resting lung volume (27). The transient decrease in airway pressure and the corresponding airflows during the expiratory phase (Figs. 1 and 5) likely prevented elevation of end-expiratory lung volume and $\mathrm{P} \overline{\mathrm{aw}}$ in normal rabbits at high rates of HFFI. However, because Paw during HFFI in the BAL group exceeded

Table 2. $P_{D}$ during conventional ventilation and $H H F I^{*}$

\begin{tabular}{ccccccc}
\hline Rate (cps) & $\mathrm{C}$ & 4 & 6 & 8 & 10 & 12 \\
\hline Normal & & & & & & \\
PDInsp & 0.34 & 6.61 & 6.81 & 6.63 & 6.17 & 5.77 \\
P Exp & 0.24 & 2.01 & 2.02 & 2.03 & 1.95 & 1.73 \\
& & & & & & \\
Bal & & & & & & \\
P Insp & 0.27 & 5.11 & 6.36 & 5.58 & 6.31 & 5.42 \\
P $_{D}$ Exp & 0.36 & 1.55 & 1.49 & 1.73 & 1.51 & 1.53 \\
\hline
\end{tabular}

${ }^{*} \mathrm{P}_{\mathrm{D}}$ computed from the flow velocity at the distal end of the tracheal cannula. $C$, conventional ventilation; Insp, inspiratory phase; Exp. expiratory phase. Units of $P_{D}$ are $c \mathrm{H}_{2} \mathrm{O}$. Note the large values of $\mathrm{P}_{D}$ during HFFI. the applied PEEP suggests that the effect of the active expiratory phase does not counteract intrinsic PEEP in sick lungs.

Although we have reported on HFFI as an independent mode of ventilation, it should be noted that the ventilator offers the option of combining HFFI with conventional ventilation. A ventilation routine that consists of high frequency and conventional modes can improve oxygenation by increasing mean lung volume and yet maintain comparatively lower $\mathrm{PaCO}_{2}$ and airway pressures than conventional ventilation alone (28). Intermittent conventional inflations, or sighs, combined with HFFI may improve gas exchange in neonates with respiratory distress syndrome but our data on BAL rabbits suggests that airway pressures may not be significantly reduced.

In summary, we found that the Infant Star flow interruption ventilator can maintain adequate gas exchange in normal as well as surfactant depleted rabbits both at conventional settings and during HFFI at rates of $4,6,8,10$, and $12 \mathrm{cps}$. The ventilator generates comparatively high peak airway pressures and airflows during HFFI primarily due to the short duration of its inspiratory phase. No gas trapping was observed in normal rabbits and a PEEP of $4 \mathrm{~cm} \mathrm{H}_{2} \mathrm{O}$ was needed to ventilate the rabbits with respiratory distress. The $\mathrm{V}_{\mathrm{T}}$ required during HFV were independent of frequency as were the maximum inspiratory and expiratory flow rates. The peak inspiratory flow velocities exceeded the peak expiratory velocities by about $60 \%$ possibly influencing mucus clearance from the airways.

Acknowledgments. The authors thank Infrasonics Inc. for providing the Infant Star ventilator used for this study and Wilber Huang and Jenny Jiao for their assistance.

\section{REFERENCES}

1. Stark AR, Frantz ID 1986 Respiratory distress syndrome. Pediatr Clin North Am 33:533-544

2. Stocks J, Godfrey S 1976 The role of artificial ventilation, oxygen and CPAP in the pathogenesis of lung damage in neonates: assessment by serial measurement of lung function. Pediatrics 57:352-362

3. Hamilton PP, Onayemi A, Smith JA, Gillan JE, Cutz E, Froese AB, Bryan AC 1983 Comparison of conventional and high frequency ventilation: oxygenation and lung pathology. J Appl Physiol 55:131-138

4. Chang HK, Harf A 1984 High frequency ventilation: a review. Respir Physiol $57: 135-152$

5. Drazen JM, Kamm RD, Slutsky AS 1984 High frequency ventilation. Physio Rev 64:505-543

6. Frantz ID, Close RH 1985 Elevated lung volume and alveolar pressure during jet ventilation of rabbits. Am Rev Respir Dis 131:134-138

7. Carlo WA, Chatburn RL, Martin RJ 1987 Randomized trial of high frequency jet ventilation versus conventional ventilation in respiratory distress syndrome. J Pediatr 110:275-282

8. Fredberg JJ, Glass GM, Boynton BR, Frantz ID 1987 Factors influencing mechanical performance of neonatal high-frequency ventilators. $J$ Appl Physiol 62:2485-2490

9. Jackson AC, Vinegar A 1979 A technique for measuring frequency response of pressure, volume and flow transducers. J Appl Physiol 47:462-467

10. Altman PL, Dittmer D 1971 Biological handbook: respiratory and circulation Federation of American Societies for Experimental Biology, Washington, DC, pp 56-59

11. Wright K, Lyrene RK, Troug WE, Standaert TA, Murphy J, Woodrum DE 1981 Ventilation by high frequency oscillation in rabbits with oleic acid lung disease. J Appl Physiol 50:1056-1060

12. Douglas FG, Chong PY, Finlayson DC 1974 Effect of artificial ventilation on lung mechanics in dogs. J Appl Physiol 37:324-328

13. Gilbert R, Keighley JF 1974 The arterial/alveolar oxygen tension ratio. An index of gas exchange applicable to varying inspired oxygen concentrations. Am Rev Respir Dis 109:142-145

14. Lachmann B, Robertson B, Vogel J 1980 In vivo lung lavage as an experimental model of the respiratory distress syndrome. Acta Anaesth Scand 24:231-236

15. Nicholas TE, Barr HA 1983 The release of surfactant in rat lung by brief periods of hyperventilation. Respir Physiol 52:69-83

16. Lachmann B, Jonson B, Lindroth M, Robertson B 1982 Modes of artificial ventilation in severe respiratory distress syndrome. Lung function and morphology in rabbits after wash-out of alveolar surfactant. Crit Care Med 10:724-732

17. Bargeton D, Barres G 1969 Time characteristics and frequency response of body plethysmograph. Prog Res Res 4:2-23

18. Chakravarti IM, Laha RG, Roy J 1967 Handbook of Methods of Applied Statistics. John Wiley and Sons, New York

19. Fletcher PR, Epstein RA 1982 Constancy of physiological dead space during 
high frequency ventilation. Respir Physiol 47:39-49

20. Weisberger SA, Carlo WA, Chatburn RL, Fouke JM, Martin RJ 1986 Effect of varying inspiratory and expiratory times during high frequency jet ventilation. J Pediatr 108:596-600

21. Smith RB 1982 Ventilation at high respiratory frequencies. Anaesthesia $37: 1011-1018$

22. Slutsky AS, Kamm RD, Rossing TH, Loring SH, Lehr J, Shapiro AH, Ingram RH, Drazen JM 1981 Effects of frequency, tidal volume and lung volume on $\mathrm{CO}_{2}$ elimination in dogs by high frequency $(2-30 \mathrm{~Hz})$ low tidal volume ventilation. J Clin Invest 68:1475-1484

23. Chartrand DA, Phillips DM, Sun RY, Harf A, Chang HK 1987 Gas exchange and hemodynamics during high frequency body surface oscillation in rabbits. Bull Eur Physiopathol Respir 23:473-478

24. Isabey D, Harf A, Chang HK 1984 Alveolar ventilation during high frequency oscillation: core dead space concept. J Appl Physiol 56:700-707

25. Chang HK, King M, Weber ME 1988 Mucus transport by high frequency nonsymmetrical oscillatory air flow. J Appl Physiol (in press)

26. Nordin U, Kain M, Keszler H 1982 Electron-microscopic studies of tracheal mucosa after high frequency jet ventilation. Crit Care Med 10:211 (abstr)

27. Bancalari A, Gerhardt T, Bancalari E, Suguihara C, Hehre D, Reifenberg L, Goldberg RN 1987 Gas trapping with high frequency ventilation: jet versus oscillatory ventilation. J Pediatr 110:617-622

28. Boynton BR, Mannino FL, Davis RF, Kopotic RJ, Friederichsen G 1984 Combined high-frequency oscillatory ventilation and intermittent mandatory ventilation in critically ill neonates. J Pediatr 105:297-302

29. Marchak BE, Thompson WK, Duffty P, Miyaki T, Bryan MH, Bryan AC, Froese AB 1981. Treatment of RDS by high frequency oscillatory ventilation: a preliminary report. J Pediatr 99:287-292 